\title{
No Evidence for the Involvement of Leiomodin-1 Antibodies in the Pathogenesis of Onchocerciasis-Associated Epilepsy
}

\author{
An Hotterbeekx ${ }^{1,2, *}$ (), Melissa Krizia Vieri ${ }^{1}{ }^{10}$, Melanie Ramberger ${ }^{3}$, Ashraf Jozefzoon-Aghai ${ }^{3}$, Michel Mandro ${ }^{4}$, \\ Floribert Tepage ${ }^{5}$, Alfred Dusabimana ${ }^{1} \mathbb{1}$, Samir Kumar-Singh ${ }^{2}$, Maarten J. Titulaer ${ }^{3}$ and Robert Colebunders ${ }^{1} \mathbb{C}$ \\ 1 Global Health Institute, University of Antwerp, 2610 Antwerp, Belgium; krizia.vieri@uantwerpen.be (M.K.V.); \\ alfred.dusabimana@uantwerpen.be (A.D.); robert.colebunders@uantwerpen.be (R.C.) \\ 2 Molecular Pathology Group, Laboratory of Cell Biology and Histology, University of Antwerp, \\ 2610 Antwerp, Belgium; Samir.kumarsingh@uantwerpen.be \\ 3 Department of Neurology, Erasmus MC University Medical Center, 3015 Rotterdam, The Netherlands; \\ ramberger.melanie@gmail.com (M.R.); a.aghai@erasmusmc.nl (A.J.-A.); m.titulaer@erasmusmc.nl (M.J.T.) \\ 4 Provincial Health Division of Ituri, Ministry of Health, Bunia, Democratic Republic of the Congo; \\ michelmandro8@gmail.com \\ 5 Ministry of Health, Buta, Democratic Republic of the Congo; floritepage@yahoo.fr \\ * Correspondence: an.hotterbeekx@uantwerpen.be; Tel.: +32-(32)-658915
}

Citation: Hotterbeekx, A.; Vieri, M.K.; Ramberger, M.; JozefzoonAghai, A.; Mandro, M.; Tepage, F.; Dusabimana, A.; Kumar-Singh, S.; Titulaer, M.J.; Colebunders, R. No Evidence for the Involvement of Leiomodin-1 Antibodies in the Pathogenesis of OnchocerciasisAssociated Epilepsy. Pathogens 2021, 10, 845. https://doi.org/10.3390/ pathogens10070845

Academic Editor: Lawrence S. Young

Received: 4 June 2021

Accepted: 1 July 2021

Published: 5 July 2021

Publisher's Note: MDPI stays neutral with regard to jurisdictional claims in published maps and institutional affiliations.

Copyright: (c) 2021 by the authors. Licensee MDPI, Basel, Switzerland. This article is an open access article distributed under the terms and conditions of the Creative Commons Attribution (CC BY) license (https:/ / creativecommons.org/licenses/by/ $4.0 /)$.

\begin{abstract}
Nodding syndrome has been suggested to be triggered by neurotoxic leiomodin-1 autoantibodies cross-reacting with Onchocerca volvulus. Here, we screened serum and CSF samples of persons with nodding syndrome and other forms of onchocerciasis-associated epilepsy (OAE) and African and European controls for leiomodin-1 antibodies by a cell-based assay (CBA) and Western blot (WB). These samples were also investigated for the presence of auto-antibodies cross-reacting with rat brain tissue by immunohistochemistry (IHC). Additionally, IHC was used to detect the leiomodin-1 protein in post-mortem brain samples of persons with OAE who died. Leiomodin-1 antibodies were detected by CBA in 6/52 (12\%) and by WB in 23/54 (43\%) persons with OAE compared to in $14 / 61(23 \%)(p=0.113)$ and $23 / 54(43 \%)(p=0.479)$ of controls without epilepsy. Multivariable exact logistic regression did not show an association between $O$. volvulus infection or epilepsy status and the presence of leiomodin-1. Leiomodin-1 antibodies were not detected in 12 CSF samples from persons with OAE or in 16 CSF samples from persons with acute-onset neurological conditions, as well as not being detected in serum from European controls. Moreover, the leiomodin-1 protein was only detected in capillary walls in post-mortem brain tissues and not in brain cells. IHC on rat brain slides with serum samples from persons with OAE or controls from persons with or without $O$. volvulus infection revealed no specific staining pattern. In conclusion, our data do not support OAE to be an autoimmune disorder caused by leiomodin-1 antibodies.
\end{abstract}

Keywords: onchocerciasis-associated epilepsy; nodding syndrome; leiomodin-1; autoimmune

\section{Introduction}

Nodding syndrome and other forms of onchocerciasis-associated epilepsy (OAE) are characterized by an onset of seizures between the age of 3 and 18 years [1]. The pathological mechanism of this type of epilepsy remains unknown but seems to be dependent on the $O$. volvulus microfilarial load. This suggests that $O$. volvulus may directly or indirectly trigger epilepsy. However, no parasites have been detected in the cerebrospinal fluid (CSF) or brains of people with OAE, indicating that parasites are not likely to invade the central nervous system directly [2,3]. Moreover, post-mortem brains of people who died with nodding syndrome and other forms of OAE showed signs of neuro-inflammation and deposition of tau-reactive neurofibrillary tangles and threads, but no evidence of a parasitic infection [2,4]. It has been suggested that OAE is an autoimmune disease caused by cross-reacting antibodies against $O$. volvulus tropomyosin and human leimodin- $1[5,6]$. 
This hypothesis is based on antibodies reacting with leiomodin- 1 which have been detected more frequently in the serum and CSF of persons with nodding syndrome compared to healthy village controls, and cross-reacting with $O$. volvulus lysates [5].

Leiomodin-1 is an intracellular protein containing an actin-binding domain and is expressed in various smooth muscle cells, including endothelial cells, the intestinal wall and the bladder $[7,8]$. Leiomodin- 1 shows similarity to the tropomodulins, but, currently, very limited information is available on the function of leiomodin-1, and the transcription profile is incomplete [7]. Recently, the presence of leiomodin-1 has been shown in the hippocampus and cerebellum of the brain of mouse brains [5], whereas the production in the human brain is limited [9]. Investigation of the Human Protein Atlas shows that leiomodin-1 is mainly expressed in endothelial cells in the human brain and in a limited amount of positive neurons $[9,10]$. However, a recent study suggested that leiomodin-1 was expressed on the membrane of newly formed neurons, but not on neural progenitor cells or mature neurons [6]. Moreover, leiomodin-1 antibodies were only toxic to cells expressing leiomodin-1 on the membrane [6].

There are also several arguments against the hypothesis that nodding syndrome is an autoimmune disease caused by leiomodin-1 antibodies. First, these antibodies have only been detected in half of the children with nodding syndrome (53\%) and were also present in $31 \%$ of controls $[5,11]$. Furthermore, leiomodin- 1 was shown to be most abundant in the hippocampus region of the mouse brain [5], whereas post-mortem brains showed no overt pathological changes in the hippocampus [2,4]. Moreover, these leiomodin-1 antibodies could be markers of disease propagation and not markers of disease initiation. In conclusion, the role of leiomodin-1 antibodies in the development of nodding syndrome remains unclear.

Therefore, this study aimed to identify leiomodin-1 antibodies in the serum and CSF of persons with nodding syndrome and other forms of OAE from the DRC and South Sudan. We also screened these samples for the presence of other antibodies cross-reacting with the central nervous system. In addition, we studied leiomodin-1 expression in various in vitro neuronal cells and post-mortem brains of persons with OAE who died.

\section{Materials and Methods}

\subsection{Study Participants and Sample Collection}

Serum samples were obtained from two village matched case-control studies in the DRC to identify risk factors for epilepsy in onchocerciasis-endemic areas, one in Ituri [12] and one in Bas Uéle [13], a clinical trial assessing the effect of ivermectin on the frequency of seizures in O. volvulus-infected persons with epilepsy [14], controls with and without O. volvulus infection from a rapid epidemiological mapping of onchocerciasis (REMO) study in Ituri [15] and a diagnostic study among patients admitted to the Mosango general hospital, in Kwilu Province [16] (Table 1). CSF samples of cases were obtained from persons with OAE from Maridi, an onchocerciasis-endemic region in South Sudan, and from persons without $O$. volvulus infection with acute-onset neurological conditions from the Mosango general hospital in Kwilu, DRC (Table 2).

Table 1. Study participants of whom serum samples were analyzed for presence of leiomodin-1 antibodies.

\begin{tabular}{ccc}
\hline Region and Type of Study & Study Participants & Number \\
\hline Ituri Province, Logo health zone, clinical trial & OAE, skin snip and/or OV16 RDT positive & 54 \\
[14], case-control study [12,13], REMO study [15] & No epilepsy, O. volvulus infection & 42 \\
& No epilepsy and no O. volvulus infection ${ }^{1}$ & 19 \\
Epilepsy centers and academic hospitals, the & Focal epilepsy without antibodies associated & 12 \\
Netherlands [18] & with encephalitis & 4 \\
\hline
\end{tabular}

${ }^{1}$ Skin snips were not obtained, but men were considered not to be infected with O. volvulus in the absence of subcutaneous Onchocerca nodules together with a negative OV16 RDT. 
Table 2. Study participants of which cerebrospinal fluid samples were analyzed for the presence of leiomodin-1 antibodies.

\begin{tabular}{ccc}
\hline Region & Study Participants & Number \\
\hline Maridi, South Sudan [3] & OAE & 12 \\
Mosango hospital, Kwilu & Acute-onset neurological \\
Province, DRC [16] & conditions & 16 \\
\hline
\end{tabular}

A person was considered to present OAE if he/she had a previously healthy child, lived in an onchocerciasis meso- or hyper-endemic area and developed epilepsy between the ages of 3 and 18 years without any obvious reason (criteria of the OAE definition) [17]. Onchocerciasis antibodies were detected using the OV16 rapid diagnostic test (OV16 RDT, SD Bioline Onchocerciasis IgG4 rapid test, Abbott Standard Diagnostics, Inc., Yongin, Republic of Korea). For comparison, 16 Dutch sera were tested as controls (12 patients with chronic focal epilepsy without antibodies associated with encephalitis, and 4 healthy persons) [18]. All 12 persons with OAE from Maridi had high $\mathrm{mf}$ densities ( $>80 \mathrm{mf} / \mathrm{skin}$ snip), but in none of the samples was DNA of O. volvulus, nor Wolbachia, the bacterial endosymbiont, found [3].

\subsection{Detection of Anti-Leiomodin-1 Antibodies in a Cell-Based Assay}

Screening for the presence of anti-leiomodin- 1 antibodies was conducted in serum (dilution 1:40) and CSF (dilution 1:2) of cases and controls using HEK-293 cells expressing recombinant leiomodin-1. HEK-293 cells were cultured in Dulbecco's modified Eagle medium (Dulbecco) for 1 day and subsequently transfected with a plasmid containing GFPtagged recombinant leiomodin-1 (origene RG209941, vector PCMV-AC with ampicillin resistance marker) for 3 min in FuGENE HD transfection reagent (Promega). Transfected cells were fixed with $4 \%$ paraformaldehyde and permeabilized with $0.2 \%$ Triton in PBS. Fixed cells were first incubated with $0.5 \%$ BSA, and consecutively with samples or primary anti-leiomodin-1 antibody as a positive control (ab104858, Protech 15117-1) for $1 \mathrm{~h}$ at room temperature, followed by staining with cy3-conjugated donkey anti-human antibody (Jackson Immuno Research 709-166-149) for $1 \mathrm{~h}$ at room temperature. Serum from a healthy European volunteer was used as a background control. Slides were mounted with Vectashield (H-1500 hard set), and cells were visualized by fluorescence microscopy (Nikon eclipse 80i).

\subsection{Detection of Anti-Leiomodin-1 Antibodies by Western Blot}

In addition to the cell-based assay, serum and CSF were also screened for the presence of leiomodin- 1 antibodies by Western blot. Recombinant leiomodin- 1 was produced by transfected HEK293 cells (origene RG209941, vector PCMV-AC with ampicillin resistance marker). To extract the leiomodin-1 protein fraction, cells were first washed with phosphate buffered saline followed by lysis in lysis buffer containing $50 \mathrm{mM}$ Tris $\mathrm{HCl}, 150 \mathrm{mM}$ $\mathrm{NaCl}$ and $1 \mathrm{mM}$ EDTA. Next, cells were disrupted by sonication and centrifuged. The supernatant containing the protein fraction from the cytoplasma was collected and stored separately. The remaining pellet containing the membrane protein was subjected to another lysis step with lysis buffer containing $50 \mathrm{mM}$ Tris $\mathrm{HCl}, 150 \mathrm{mM} \mathrm{NaCl}, 1 \mathrm{mM}$ EDTA and $1 \%$ triton-x-100:protease inhibitor (1:25). Proteins in each fraction were precipitated and quantified using the Pierce ${ }^{\mathrm{TM}}$ BCA Protein Assay Kit (Thermo Scientific, Waltham, MA, USA) according to the manufacturer's instructions. Next, $2 \mu \mathrm{g}$ of protein fraction was run on a NuPAGE polyacrylamide gel for $90 \mathrm{~min}$ and $100 \mathrm{~V}$. Protein fractions were blotted in a nitrocellulose membrane for $60 \mathrm{~min}$ at $100 \mathrm{~V}$. Nitrocellulose membranes were blocked with $5 \%$ bovine serum albumin, followed by incubation with the sample at $4{ }^{\circ} \mathrm{C}$. Serum samples were diluted 1:500 prior to blotting, and CSF samples were diluted 1:50. Commercial primary anti-leiolodin-1 antibody (Rabbit polyclonal, abcam, ab104858) was diluted 1:500 and used as a positive control. Swine anti-rabbit HRP or polyclonal rabbit anti-human HRP (Dako) was used as secondary antibody at a dilution of 1:1000. The blots were developed 
using BM Chemiluminescence Western blotting substrate (Sigma Aldrich, Saint-Louis, MO, USA).

\subsection{Immunohistochemistry to Screen for Auto-Antibodies in Serum Samples}

To screen for the presence of auto-antibodies cross-reacting with brain tissue, rat brain slides were prepared for immunohistochemistry, as described before [19]. Briefly, $8 \mu \mathrm{m}$ slides including an intact cerebellum and hippocampus were prepared in Superfrost Plus slides (Thermo Fisher Scientific, Waltham, MA, USA) and blocked with 1\% bovine serum albumin in phosphate buffered saline for $30 \mathrm{~min}$. Serum (diluted 1:200) or CSF (diluted 1:2) from cases and controls was applied on the brain slides and incubated overnight at $4{ }^{\circ} \mathrm{C}$. After washing, slides were incubated with goat anti-human IgG (Heavy + Light, biotinylated; Vector Laboratories Inc., BA-3000; dilution 1:2000) for $2 \mathrm{~h}$, followed by incubation with Avidin \& Biotinylated horseradish peroxidase macromolecular Complex vectastain (Vector Laboratories Inc., Elite kit, Pk 6100, Burlingame, CA, USA). Slides were developed with 3,3'-Diaminobenzidine (Kit 6-SK-4105, Vector Laboratories Inc. (Brunschwig Chemie, Basel, Switzerland), counterstained with hematoxylin and examined by light microscopy (Olympus BX50F) for specific staining patterns, blinded for patient status.

\subsection{Immunohistochemistry to Detect the Presence of Leiomodin-1 in Post-Mortem Brains of People} with OAE Who Died

Immunohistochemistry was used to detect the presence of leiomodin-1 in post-mortem brains of people with OAE who died in northern Uganda (Table 3). The post-mortem material and the study population have been described before [2]. Formalin-fixed paraffinembedded brain tissue slides were deparaffinized followed by antigen retrieval by boiling in citric acid buffer in a microwave. Endogenous peroxidases were blocked in $\mathrm{H}_{2} \mathrm{O}_{2}$, and non-specific binding sites were blocked in normal horse serum. Samples were incubated overnight with rabbit anti-leiomodin-1 antibody (1:100 dilution; ab 104858, abcam) at $4{ }^{\circ} \mathrm{C}$. After washing, the slides were incubated with biotinylated Donkey anti-rabbit secondary antibody (dilution 1:200; Abcam) for $30 \mathrm{~min}$ and conjugated with Extravidinperoxidase (Sigma Aldrich, Saint-Louis, MO, USA). The slides were developed with 3,3'Diaminobenzidine, counterstained with hematoxylin and visualized by light microscopy. A formalin-fixed paraffin-embedded human colon was used as the positive control, and incubation with the secondary antibody was omitted as the negative control.

Table 3. Selected brain regions for leiomodin-1 immunohistochemistry.

\begin{tabular}{|c|c|c|c|c|c|c|}
\hline Case 1 & Case 2 & Case 3 & Case 4 & Case 5 & Control 1 & Control 2 \\
\hline $\begin{array}{l}\text { Hippocampus } \\
\text { (dentate gyrus) } \\
\text { Hippocampus + } \\
\text { amygdala }\end{array}$ & $\begin{array}{l}\text { Hippocampus } \\
\text { (dentate gyrus) } \\
\text { Cerebellum } \\
\text { cortex } \\
\text { Cerebellum } \\
\text { vermis } \\
\text { Frontal cortex } \\
\text { Caudate nucleus } \\
\text { Primary motor } \\
\text { cortex } \\
\text { Parietal cortex }\end{array}$ & $\begin{array}{c}\text { Hippocampus } \\
\text { (dentate gyrus) } \\
\text { Hippocampus } \\
\text { anterior part } 1 \\
\text { Hippocampus } \\
\text { anterior part } 2 \\
\text { Hippocampus } \\
\text { anterior part } 3 \\
\text { Cerebellum } \\
\text { cortex } \\
\text { Cerebellum } \\
\text { vermis }\end{array}$ & $\begin{array}{c}\text { Hippocampus } \\
\text { (dentate gyrus) } \\
\text { Hippocampus } \\
\text { Cerebellum } \\
\text { cortex } \\
\text { Cerebellum } \\
\text { vermis }\end{array}$ & $\begin{array}{c}\text { Cerebellum vermis } \\
\text { Thalamus + corpus } \\
\text { mamillaria } \\
\text { Hypothalamus } \\
\text { anterior + corpus } \\
\text { mamillaria } \\
\text { Hypothalamus } \\
\text { posterior + corpus } \\
\text { mamillaria } \\
\text { Superior gyrus of the } \\
\text { temporal lobe }\end{array}$ & $\begin{array}{l}\text { Hippocampus } \\
\text { Cerebellum } \\
\text { cortex } \\
\text { Frontal cortex } \\
\text { Sulcus } \\
\text { calcarinus }\end{array}$ & $\begin{array}{l}\text { Hippocampus } \\
\text { Cerebellum } \\
\text { cortex } \\
\text { Frontal cortex }\end{array}$ \\
\hline
\end{tabular}

\subsection{Statistics}

Clinical and demographic variables were presented using the median and interquartile range (IQR) for continuous variables and absolute and relative frequencies for categorical variables. Fisher's exact test was used to compare the categorical variables and Wilcoxon 
sum rank test for continuous variables. Multivariable exact logistic regression including age, gender, $O$. volvulus infection and epilepsy status was used to determine factors associated with the presence of leimodin-1. Data were analyzed using SAS version 9.4, SAS Institute Inc. Cary, NC, and R version 4.0.2. A two-sided 5\% significance level was used.

\section{Results}

\subsection{Leiomodin-1 Antibodies in Serum and CSF}

In total, we analyzed 115 sera by a cell-based assay and Western blot. Leiomodin-1 antibodies were detected in the serum of 6/52 (12\%) persons with OAE compared to 14/61 $(23 \%)$ controls without epilepsy $(p=0.113)$ by a cell-based assay (Tables 4 and 5 , Figure 1$)$. Using Western blot, these antibodies were detected in 23/54 (43\%) persons screened with OAE (including in 5/22 [23\%] with nodding seizures) and 30/61 (49\%) controls without epilepsy (Table $4, p=0.479$ ). We did not observe a significant difference in leiomodin1 antibody prevalence between cases and controls when considering a double positive test (cell-based assay positive and Western blot positive) or only one of the positive tests (Table 4).

Table 4. Presence of leiomodin-1 antibodies in serum from persons with OAE and persons without epilepsy from Ituri Province, DRC.

\begin{tabular}{cccc}
\hline Parameter & $\begin{array}{c}\text { Persons with OAE } \\
(\mathbf{N}=\mathbf{5 4})\end{array}$ & $\begin{array}{c}\text { Controls without Epilepsy } \\
\mathbf{( N = 6 1 )}\end{array}$ & $p$-Value \\
\hline Age (median, IQR) & $19(14-23)$ & $31(15.5-46.5)$ & $<0.001$ \\
Male (N, \%) & $30(55 \%)$ & $49(80 \%)$ & 0.004 \\
Nodding seizures (N, \%) & 16 & NA & NA \\
Age of seizure onset (median, IQR) & $10(7-13)$ & $11(19 \%)$ & 0.091 \\
Ever treated with ivermectin (N, \%) & $4(7 \%)$ & $14(23 \%)$ & 0.113 \\
Leiomodin-1 antibodies by CBA (N, \%) & $6 / 52(11 \%)$ & $30(49 \%)$ & 0.479 \\
Leiomodin-1 antibodies by WB (N, \%) & $23 / 54(43 \%)$ & $12(20 \%)$ & 0.136 \\
Leiomodin-1 antibodies positive, CBA and & $5 / 52(10 \%)$ & $32(52 \%)$ & 0.391 \\
WB (N, \%) & & \\
Leiomodin-1 antibodies positive, CBA or & $24 / 54(44 \%)$ & & \\
WB (N, \%) &
\end{tabular}

IQR: interquartile range; NA: not applicable; CBA: cell-based assay; * CBA not conducted in two persons; WB: Western blot.

Table 5. Prevalence of serum leiomodin-1 antibodies in serum from O. volvulus-infected and non-infected individuals.

\begin{tabular}{cccc}
\hline & Ov $+(N=96)$ & Ov- $(N=19)$ & $p$-Value \\
Leiomodin-1 CBA+ $(N, \%)$ & $17(18 \%)$ & $3(16 \%)$ & 0.840 \\
Leiomodin-1 WB $+(N, \%)$ & $O v+(N=96)$ & $O v-(N=19)$ & 0.587 \\
Leiomodin-1 antibodies positive, CBA and WB $(N, \%)$ & $17(18 \%)$ & $10(53 \%)$ & 0.397 \\
\hline
\end{tabular}

Ov: O. volvulus; CBA: cell-based assay; WB: Western blot.

The sera of 96 O. volvulus-infected persons were tested by a cell-based assay, of which $17(18 \%)$ tested positive for leiomodin-1 antibodies compared to 3/19 (16\%) persons without O. volvulus infection $(p=0.840)$. Similarly, of 96 O. volvulus-infected persons tested by Western blot, $44(46 \%)$ tested positive for leiomodin-1 antibodies compared to 14 (48\%) of 29 persons without $O$. volvulus infection $(p=0.587)$ (Table 5). Furthermore, no leiomodin-1 antibodies were found in 12 CSF samples from persons with OAE, nor in 16 CSF samples from persons with acute-onset neurological conditions. Leiomodin was also not found in the serum of 12 Dutch persons with epilepsy or 4 healthy controls.

In multivariable analysis using a cell-based assay, leiomodin- 1 antibodies were more likely to be present in males than females (Table 6). However, using Western blot, only increasing age increased the odds of leiomodin- 1 antibodies. No association was found between $O$. volvulus infection or epilepsy status and the presence of leiomodin-1 using a cell-based assay or Western blot (Table 6). 

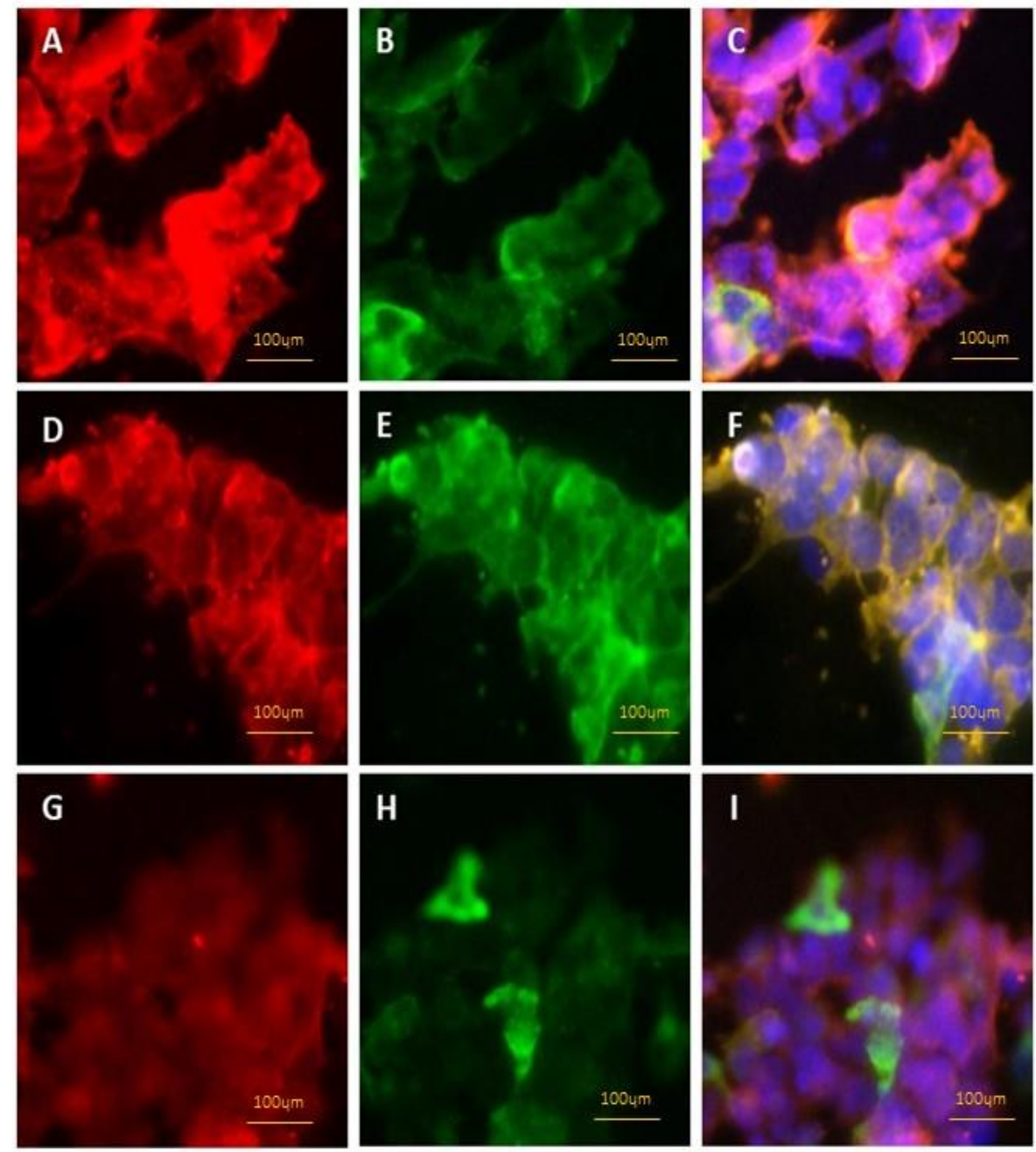

\section{HEK293 cells transfected with vector + LMOD1}

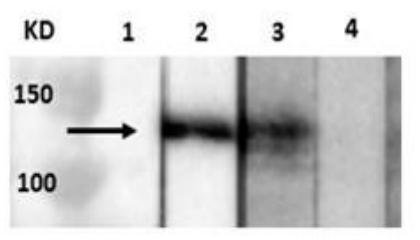

HEK293 cells untransfected

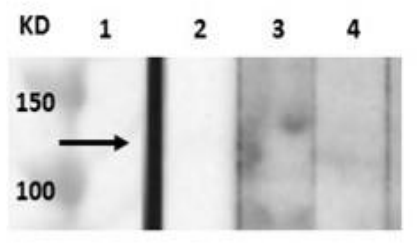

Figure 1. Detection of leiomodin-1 antibodies by cell-based assay (left panel) and Western blot (right panel). (A-C): cellbased assay with a positive sample; (D-F): cell-based assay with a negative sample; (G-I): cell-based assay showing human IgG staining. Red: human leiomodin-1 antibodies; green: leiomodin-1 transfection with GFP tag; blue: $4^{\prime}$,6-diamidino-2fenylindool. Right panel: Western blot of the commercial leiomodin-1 antibody (lane 2), a positive sample (lane 3) and a negative sample (lane 4) with transfected HEK293 cells (upper right panel) and untransfected cells (lower right panel) as a negative control.

Table 6. Exact logistic regression to assess factors associated with the presence of leiomodin-1 antibody detected by cell-based assay or Western blot.

\begin{tabular}{cccccccccc}
\hline & \multicolumn{3}{c}{ Cell-Based Assay } & \multicolumn{3}{c}{ Western Blot } \\
\hline Parameter & Estimate & \multicolumn{2}{c}{$\mathbf{9 5 \%}$ CI } & $\boldsymbol{p}$-Value & Estimate & $\mathbf{9 5 \% C I}$ & $\boldsymbol{p}$-Value \\
\hline Gender (Male vs. Female) & 3.599 & 1.271 & 24.836 & 0.007 & 1.352 & 0.821 & 2.270 & 0.278 \\
Age (years) & 0.977 & 0.940 & 1.014 & 0.230 & 1.033 & 1.003 & 1.065 & 0.031 \\
Persons with (OAE vs. control & 0.528 & 0.237 & 1.106 & 0.100 & 1.142 & 0.680 & 1.962 & 0.757 \\
without epilepsy) & 1.777 & 0.794 & 4.672 & 0.208 & 1.029 & 0.525 & 2.020 & 0.928 \\
\hline O. volvulus-infected vs. no infection & & & & & & &
\end{tabular}

3.2. Immunohistochemistry to Screen for Auto-Antibodies and of Post-Mortem Brains of People with OAE Who Died

Sera of 170 persons with epilepsy from onchocerciasis-endemic areas and 152 persons without epilepsy were screened for the presence of auto-antibodies by immunohistochemistry on rat brain slides. These 170 cases and 152 controls were included in several 
epidemiological studies in the Ituri [12], Bas Uélé [13] and Kwilu [16] provinces of the DRC and Maridi County in South Sudan [3].

In none of their sera was any specific staining pattern identified. Immunohistochemistry with commercial leiomodin-1 antibodies on human tissue showed leiomodin-1 staining in the smooth muscle cells of the human colon positive control and in the endothelial cells of the blood vessels in the human post-mortem brain samples (Figure 2). Very weak or non-specific staining was observed in neuronal cells (Figure 2). There was no difference between the brain samples from OAE cases and controls without epilepsy. These results are in accordance with the immunohistochemistry data available in the Human Protein Atlas [9].
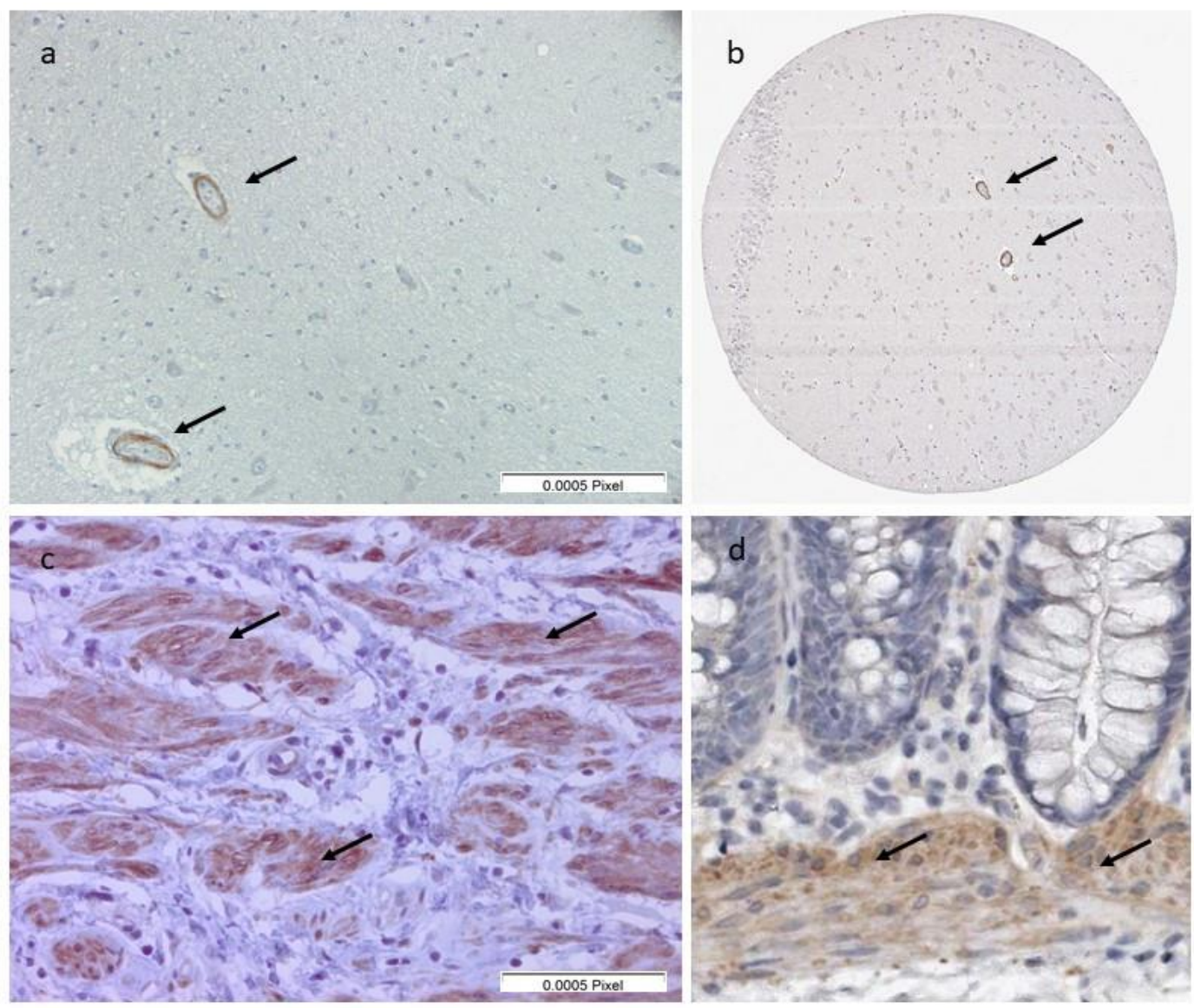

Figure 2. (a) Immunohistochemistry of post-mortem brain tissue from the hippocampal area from a person with nodding syndrome. Leiomodin-1 is detected in the blood vessels (black arrows). (b) Immunohistochemistry of post-mortem brain tissue from the hippocampal area from the Human Protein Atlas. Leiomodin-1 is detected in the blood vessels (black arrows). (c) Immunohistochemistry of colon tissue from this study. Leiomodin-1 is detected in the smooth muscle cells (black arrows). (d) Immunohistochemistry of colon tissue from the Human Protein Atlas. Leiomodin-1 is detected in the smooth muscle cells (black arrows).

\section{Discussion}

Our study does not support the hypothesis that leiomodin-1 antibodies play an etiological role in OAE. Indeed, no significant difference was observed between OAE and controls without epilepsy by the cell-based assay. Moreover, we even detected a lower prevalence of leiomodin- 1 antibodies in persons with OAE (10\%) compared to controls without epilepsy (23\%), although no significant difference was detected in these groups by Western blot, a more sensitive assay in our study. Additionally, leiomodin- 1 antibodies were not detected in the CSF of persons with OAE or persons with other neurological conditions. These results are different from an earlier study of Johnson et al., who detected 
leimodin-1 antibodies in 29/55 (53\%) children with nodding syndrome and 17/55 (31\%) unaffected village controls $(p=0.024)$, and higher antibody titers in children with nodding syndrome compared to village controls. Moreover, Johnson et al. also detected leiomodin-1 antibodies in the CSF of 8/16 (50\%) persons with nodding syndrome compared to none out of 8 North American control persons with epilepsy. Similarly, we also did not detect leiomodin-1 antibodies in any of the Dutch controls in the current study. We cannot exclude that leiomodin-1 antibodies might cross-react with other common parasites co-endemic with O. volvulus but absent in American and European populations, such as other filarial parasites or malaria.

Multivariable exact logistic regression did not show an association between O. volvulus infection or epilepsy status and the presence of leiomodin-1. This is in contrast with the study findings by Johnson et al. suggesting an association between the presence of leiomodin- 1 antibodies and $O$. volvulus infection, and a reaction of leiomodin-1 antibodies with $O$. volvulus lysates [5].

The main differences between the current study and the study by Johnson et al. are the study population and the detection method for leiomodin- 1 antibodies. First, Johnson et al. studied Ugandan children with nodding syndrome, whereas we studied Congolese persons with OAE, of which only $27 \%$ had a history of nodding seizures. However, these children had similar frequencies of leiomodin- 1 antibodies (31\%). It has been shown that persons with nodding seizures have a more severe epilepsy and higher microfilarial loads compared to persons with other forms of OAE [20,21]. In addition, Johnson et al. used an enzyme-linked immunosorbent assay (ELISA) to detect leiomodin-1 antibodies, while we used a cell-based assay and Western blot test, the latter being a more specific test for the detection of antibodies than ELISA due to the possibility to control the binding location in the cell and the size of the protein on the blot [22].

Immunohistochemistry using rat brain slices to detect the presence of brain-specific antibodies did not show any specific staining pattern. This method was developed to specifically identify antigenic targets on the membrane of neurons [23]. It has been proven to identify over ten new antibodies mediating autoimmune encephalitis, including those causing seizures [19]. As all samples tested negative, it excludes most of the known antibodies causing autoimmune encephalitis or autoimmune-associated seizures [18]. If positive, it would have guided selection for immunoprecipitation to discover novel antibodies. However, a negative result does not exclude, at all, the presence of antibodies, as human-specific antigens may not be recognized on rat brains, or conformational epitopes may be modified by the fixation techniques. Immunohistochemistry detected leiomodin-1 in the walls of the cerebral blood vessels in post-mortem brain samples of persons with OAE who died, as also presented in the Human Protein Atlas $[9,10]$.

The strength of our study is that we examined a relatively large set of samples of persons with OAE and controls, including both village controls and non-African controls. A weakness is that only a limited number of persons with OAE presented with nodding seizures. In conclusion, leiomodin- 1 antibodies do not seem be to play a role in the pathogenesis of OAE. Further research is needed to elucidate the physiopathology of OAE.

Author Contributions: Conceptualization, A.H., M.K.V., M.J.T., R.C.; methodology, A.H., M.K.V., M.J.T., R.C.; software, A.H.; validation, A.H., R.C.; formal analysis, A.H., M.K.V., A.D., M.J.T., R.C.; investigation A.H., M.K.V., A.D., M.J.T., R.C.; resources, R.C.,; data curation, A.H.; writing-original draft preparation, A.H., M.K.V., R.C.; writing-review and editing, A.H., M.K.V., M.R., A.J.-A., M.M., F.T., A.D., S.K.-S., M.J.T., R.C.; visualization, A.H.; supervision, R.C.; project administration, R.C.; funding acquisition, R.C. All authors have read and agreed to the published version of the manuscript.

Funding: This study was funded by a grant from the European Research Council (ERC 671055). The study sponsor was not involved in performing the research nor in the writing of the paper.

Institutional Review Board Statement: This study was conducted according to the guidelines of the Declaration of Helsinki and approved by the ethics committee of the School of Public Health of 
the University of Kinshasa in the DRC (ESP/CE/063/2017) and that of the University of Antwerp, Belgium (17/32/369).

Informed Consent Statement: All participants were asked to sign an informed consent form, and only consenting individuals were enrolled. Minors $>12$ years and $<18$ years signed an assent form in addition, while parents or legal guardians consented for younger participants. All individual data were encoded and treated confidentially.

Data Availability Statement: The datasets generated during the current study are available from the corresponding authors on reasonable request.

Acknowledgments: We thank Kristien Verdonck (Institute of Tropical medicine, Antwerp, Belgium) from the project "Better Diagnosis for Neglected Infectious Diseases" and the research team from Mosango hospital for providing the samples from the patients admitted at the Mosango Hospital. We als thank all the study participants.

Conflicts of Interest: The authors declare no conflict of interests.

\section{References}

1. Colebunders, R.; Nelson Siewe, F.J.; Hotterbeekx, A. Onchocerciasis-Associated Epilepsy, an Additional Reason for Strengthening Onchocerciasis Elimination Programs. Trends Parasitol. 2018, 34, 208-216. [CrossRef] [PubMed]

2. Hotterbeekx, A.; Lammens, M.; Idro, R.; Akun, P.R.; Lukande, R.; Akena, G.; Nath, A.; Taylor, J.; Olwa, F.; Kumar-Singh, S.; et al. Neuroinflammation and Not Tauopathy Is a Predominant Pathological Signature of Nodding Syndrome. J. Neuropathol. Exp. Neurol. 2019. [CrossRef]

3. Hotterbeekx, A.; Raimon, S.; Abd-Elfarag, G.; Carter, J.Y.; Sebit, W.; Suliman, A.; Fodjo, J.N.S.; De Witte, P.; Logora, M.Y.; Colebunders, R.; et al. Onchocerca volvulus is not detected in the cerebrospinal fluid of persons with onchocerciasis-associated epilepsy. Int. J. Infect. Dis. 2019. [CrossRef]

4. Pollanen, M.S.; Onzivua, S.; Robertson, J.; McKeever, P.M.; Olawa, F.; Kitara, D.L.; Fong, A. Nodding syndrome in Uganda is a tauopathy. Acta Neuropathol. 2018. [CrossRef]

5. Johnson, T.P.; Tyagi, R.; Lee, P.R.; Lee, M.H.; Johnson, K.R.; Kowalak, J.; Elkahloun, A.; Medynets, M.; Hategan, A.; Kubofcik, J.; et al. Nodding syndrome may be an autoimmune reaction to the parasitic worm Onchocerca volvulus. Sci. Transl. Med. 2017, 9. [CrossRef] [PubMed]

6. Nauen, D.W.; Haffner, M.C.; Kim, J.; Zheng, Q.; Yin, H.; DeMarzo, A.M.; Mahairaki, V.; Colantuoni, C.; Pickering, J.G.; Johnson, T.P. Putative Autoantigen Leiomodin-1 Is Expressed in the Human Brain and in the Membrane Fraction of Newly Formed Neurons. Pathogens 2020, 9, 1036. [CrossRef]

7. Nanda, V.; Miano, J.M. Leiomodin 1, a new serum response factor-dependent target gene expressed preferentially in differentiated smooth muscle cells. J. Biol. Chem. 2012, 287, 2459-2467. [CrossRef]

8. Halim, D.; Wilson, M.P.; Oliver, D.; Brosens, E.; Verheij, J.B.G.M.; Han, Y.; Nanda, V.; Lyu, Q.; Doukas, M.; Stoop, H.; et al. Loss of LMOD1 impairs smooth muscle cytocontractility and causes megacystis microcolon intestinal hypoperistalsis syndrome in humans and mice. Proc. Natl. Acad. Sci. USA 2017, 114, E2739-E2747. [CrossRef] [PubMed]

9. Human Protein Atlas. Available online: http://www.proteinatlas.org (accessed on 3 July 2021).

10. Uhlen, M.; Fagerberg, L.; Hallstrom, B.M.; Lindskog, C.; Oksvold, P.; Mardinoglu, A.; Sivertsson, A.; Kampf, C.; Sjostedt, E.; Asplund, A.; et al. Proteomics. Tissue-based map of the human proteome. Science 2015, 347, 1260419. [CrossRef] [PubMed]

11. Colebunders, R.; Titulaer, M.J. Nodding syndrome: Preventable and treatable. Sci. Transl. Med. 2017, 9. [CrossRef]

12. Mandro, M.; Suykerbuyk, P.; Tepage, F.; Rossy, D.; Ngave, F.; Hasan, M.N.; Hotterbeekx, A.; Mambandu, G.; Kashama, J.M.; Laudisoit, A.; et al. Onchocerca volvulus as a risk factor for developing epilepsy in onchocerciasis endemic regions in the Democratic Republic of Congo: A case control study. Infect. Dis. Poverty 2018, 7, 79. [CrossRef]

13. Colebunders, R.; Mandro, M.; Mokili, J.L.; Mucinya, G.; Mambandu, G.; Pfarr, K.; Reiter-Owona, I.; Hoerauf, A.; Tepage, F.; Levick, B.; et al. Risk factors for epilepsy in Bas-Uele Province, Democratic Republic of the Congo: A case-control study. Int. J. Infect. Dis. 2016, 49, 1-8. [CrossRef] [PubMed]

14. Mandro, M.; Siewe Fodjo, J.N.; Dusabimana, A.; Mukendi, D.; Haesendonckx, S.; Lokonda, R.; Nakato, S.; Nyisi, F.; Abhafule, G.; Wonya'rossi, D.; et al. Single versus Multiple Dose Ivermectin Regimen in Onchocerciasis-Infected Persons with Epilepsy Treated with Phenobarbital: A Randomized Clinical Trial in the Democratic Republic of Congo. Pathogens 2020, 9, 205. [CrossRef]

15. Hotterbeekx, A.; Perneel, J.; Mandro, M.; Abhafule, G.; Siewe Fodjo, J.N.; Dusabimana, A.; Abrams, S.; Kumar-Singh, S.; Colebunders, R. Comparison of Diagnostic Tests for Onchocerca volvulus in the Democratic Republic of Congo. Pathogens 2020, 9, 435. [CrossRef] [PubMed]

16. Mukendi, D.; Lilo Kalo, J.R.; Mpanya, A.; Minikulu, L.; Kayembe, T.; Lutumba, P.; Barbe, B.; Gillet, P.; Jacobs, J.; Van Loen, H.; et al. Clinical Spectrum, Etiology, and Outcome of Neurological Disorders in the Rural Hospital of Mosango, the Democratic Republic of Congo. Am. J. Trop. Med. Hyg. 2017, 97, 1454-1460. [CrossRef] 
17. Colebunders, R.; Siewe Fodjo, J.N.; Hopkins, A.; Hotterbeekx, A.; Lakwo, T.L.; Kalinga, A.; Logora, M.Y.; Basanez, M.G. From river blindness to river epilepsy: Implications for onchocerciasis elimination programmes. PLoS Negl. Trop. Dis. 2019, 13, e0007407. [CrossRef]

18. de Bruijn, M.; Bastiaansen, A.E.M.; Mojzisova, H.; van Sonderen, A.; Thijs, R.D.; Majoie, M.J.M.; Rouhl, R.P.W.; van CoevordenHameete, M.H.; de Vries, J.M.; Munoz Lopetegi, A.; et al. Antibodies Contributing to Focal Epilepsy Signs and Symptoms Score. Ann. Neurol. 2021. [CrossRef]

19. van Coevorden-Hameete, M.H.; Titulaer, M.J.; Schreurs, M.W.; de Graaff, E.; Sillevis Smitt, P.A.; Hoogenraad, C.C. Detection and Characterization of Autoantibodies to Neuronal Cell-Surface Antigens in the Central Nervous System. Front. Mol. Neurosci. 2016, 9, 37. [CrossRef]

20. Colebunders, R.; Abd-Elfarag, G.; Carter, J.Y.; Olore, P.C.; Puok, K.; Menon, S.; Fodjo Siewe, J.N.; Bhattacharyya, S.; Ojok, M.; Lako, R.; et al. Clinical characteristics of onchocerciasis-associated epilepsy in villages in Maridi County, Republic of South Sudan. Seizure 2018, 62, 108-115. [CrossRef] [PubMed]

21. Siewe Fodjo, J.N.; Mandro, M.; Mukendi, D.; Tepage, F.; Menon, S.; Nakato, S.; Nyisi, F.; Abhafule, G.; Wonya'rossi, D.; Anyolito, A.; et al. Onchocerciasis-associated epilepsy in the Democratic Republic of Congo: Clinical description and relationship with microfilarial density. PLoS Negl. Trop. Dis. 2019, 13, e0007300. [CrossRef]

22. Nockler, K.; Reckinger, S.; Broglia, A.; Mayer-Scholl, A.; Bahn, P. Evaluation of a Western Blot and ELISA for the detection of anti-Trichinella-IgG in pig sera. Vet. Parasitol. 2009, 163, 341-347. [CrossRef] [PubMed]

23. Ances, B.M.; Vitaliani, R.; Taylor, R.A.; Liebeskind, D.S.; Voloschin, A.; Houghton, D.J.; Galetta, S.L.; Dichter, M.; Alavi, A.; Rosenfeld, M.R.; et al. Treatment-responsive limbic encephalitis identified by neuropil antibodies: MRI and PET correlates. Brain 2005, 128, 1764-1777. [CrossRef] [PubMed] 